\title{
Stereotactic Radiosurgery to the Resection Cavity of Brain Metastases: A Retrospective Analysis and Literature Review
}

\author{
Jean-Claude M. Rwigema ${ }^{a}$ Rodney E. Wegner ${ }^{a}$ Arlan H. Mintz ${ }^{a}$ c \\ Anthony J. Paravati ${ }^{a}$ Steven A. Burton ${ }^{a}$ Cihat Ozhasoglu ${ }^{a}$ Dwight E. Heron ${ }^{a}$ b \\ Departments of a Radiation Oncology, ${ }^{b}$ Otolaryngology and ${ }^{c}$ Neurological Surgery, University of Pittsburgh \\ Cancer Institute, University of Pittsburgh School of Medicine, Pittsburgh, Pa., USA
}

\section{Key Words}

Stereotactic radiosurgery $\cdot$ Brain metastases .

Postoperative radiotherapy $\cdot$ CyberKnife $^{\circledR} \cdot$ Whole brain

radiotherapy

\begin{abstract}
Purpose: The aim of this study was to analyze results of stereotactic radiosurgery (SRS) as adjuvant therapy for resected brain metastases. Methods: Medical records of patients treated at a single institution with SRS to the postoperative cavity of brain metastases were retrospectively reviewed. Patients who completed the prescribed SRS regimen following gross-total resection and had no previous whole brain radiotherapy were included in the study. Kaplan-Meier analyses were used to estimate local (LC) and intracranial control (IC), and overall survival (OS) rates. Results: Between April 2005 and July 2010, 77 patients (median age 63 years) with 89 metastases met the inclusion criteria. The median prescription dose was $18 \mathrm{~Gy}(12-27 \mathrm{~Gy})$ delivered in 1-3 fractions for a median target volume of $7.6 \mathrm{~cm}^{3}\left(0.5-59 \mathrm{~cm}^{3}\right)$. The 6-month, 1-year, and 2-year LC rates were 76.1, 76.1, and $74.3 \%$, respectively. The 6-month, 1-year, and 2-year IC rates were $75.2,54$, and $43.6 \%$, respectively. With a median followup of 13.8 months, the median OS was 14.5 months (1.9-51.4 months) after SRS. The overall 6-month, 1-year, and 2-year
\end{abstract}

OS rates were $91,62.5$, and $43.6 \%$, respectively. Complications included 2 patients with radiation necrosis. Conclusion: Adjuvant radiosurgery to the tumor cavity of resected brain metastases is well-tolerated and achieves $L C$ in the majority of patients.

Copyright $\odot 2011$ S. Karger AG, Basel

\section{Introduction}

Every year, nearly 170,000 patients are diagnosed with brain metastases in the United States, making these lesions the most common type of brain tumor [1]. Moreover, approximately $20-40 \%$ of patients with cancer will develop brain metastases in their lifetime [2]. In addition to surgery, whole brain radiotherapy (WBRT) has been a standard therapy for brain metastases following resection [3]. However, WBRT is reported to be associated with an increased risk of toxicities, in particular neurocognitive decline in long-term survivors $[4,5]$.

Stereotactic radiosurgery (SRS) is emerging as a potentially effective therapy to prevent local recurrence of brain metastases after resection [6-10]. In this setting, SRS has been shown to provide similar local control rates as WBRT, but with an improved toxicity profile. In addition, SRS has the advantage of a shorter treatment course,

\section{KARGER}

Fax +4161306 1234 E-Mail karger@karger.ch www.karger.com

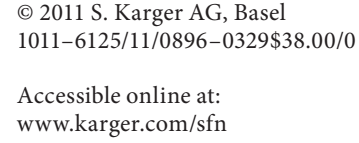

Arlan H. Mintz, MD, MSc, FACS

Department of Neurological Surgery, University of Pittsburgh School of Medicine 200 Lothrop Street, Suite 400

Pittsburgh, PA 15213 (USA)

Tel. +1 412647 7614, E-Mail hjcmr10@gmail.com 
Fig. 1. a Preoperative thin-slice $(1.2 \mathrm{~mm})$ contrast-enhanced spoiled gradient recalled acquisition in steady state sequence MRI for a patient with metastatic melanoma to the brain showing large mass surrounded by vasogenic edema. b Postoperative $\mathrm{T}_{1}$-weighted brain MRI with contrast showing the tumor bed, 11 days after craniotomy and resection but prior to SRS.
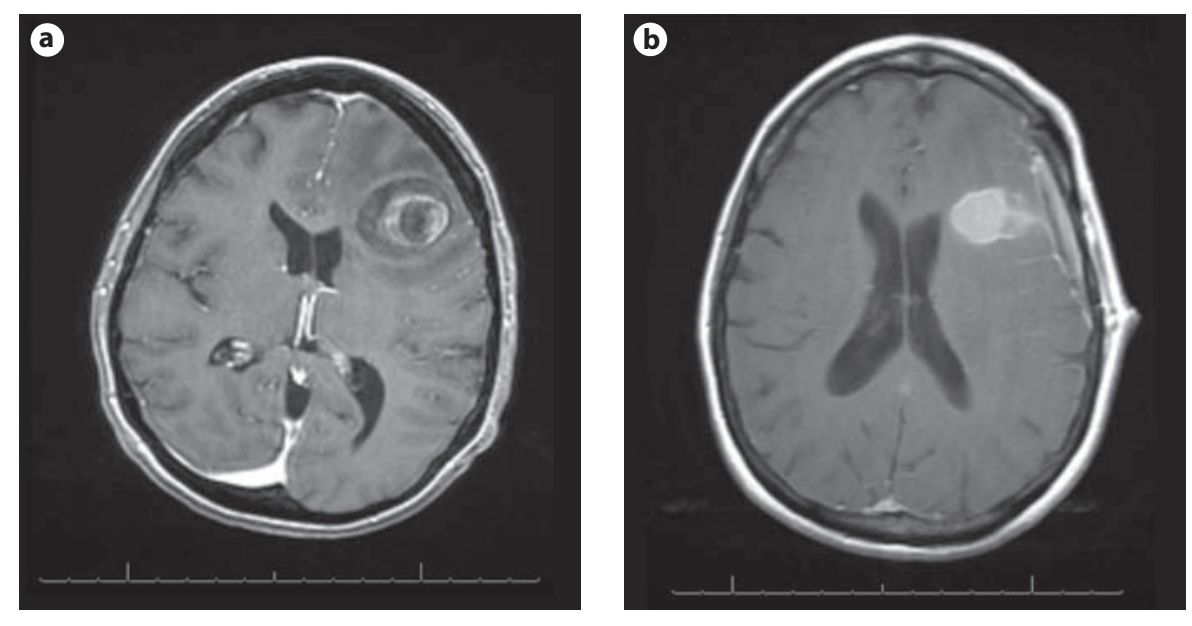

which enhances patient compliance with treatment and allows prompt initiation of systemic therapy. Currently, the literature on the use of adjuvant SRS for resected brain metastases is still limited without an RCT, and thus requires further investigation to fully assess the effectiveness of this therapy in comparison to WBRT.

At our institution, extensive clinical experience with SRS in treatment of other tumors, including head/neck and pancreatic cancers, has demonstrated considerable advantages of this novel technique over conventional radiotherapy methods $[11,12]$. In this study, we sought to further investigate the clinical application of linac-based SRS and its feasibility as adjuvant therapy for metastatic brain tumors following resection. Adjuvant radiotherapy to the tumor bed of resected brain metastases is vital, as surgical removal alone is associated with significant local recurrence rates [13]. Moreover, the use of upfront focused radiosurgery and the deferment of WBRT for patients with a limited number of brain metastases could avoid potential side effects of WBRT, such as radiationinduced alopecia, fatigue, and late effects of neurocognitive decline $[14,15]$. This strategy may result in improved quality of life for these patients.

Various prognostic indices have been developed to assess the outcomes of radiosurgery for brain tumors, including the Radiation Therapy Oncology Group recursive partitioning class (RPA) [16, 17], the Score Index for Radiosurgery [18], and the Basic Score for Brain Metastases [19]. Most recently, the graded prognostic assessment (GPA) [20] was developed, and since it is less subjective and more quantitative, we herein report its utility compared to the RPA analysis for brain metastases patients.

\section{Patients and Methods}

Study Design and Patient Selection

Medical records of patients treated with SRS in 1-3 fractions following surgical resection of brain metastases, from April 2005 to July 2010 in a single institution, were retrospectively reviewed. Criteria for surgical resection were patients with large or symptomatic lesions in accessible areas or those with single lesions in surgically accessible areas. Patients with potentially resectable brain lesions but who were undergoing systemic therapy for active primary disease were often judged not suitable for surgical resection, and received SRS to the unresected brain metastases; therefore, they were therefore not included in the study. Patients who had subtotal tumor resection were excluded from the study. Extent of resection was confirmed with postoperative MRI and surgery reports. Figure 1 shows example preoperative and postoperative MRI scans. All patients completed the prescribed SRS regimen and had WBRT only as salvage therapy after disease recurrence. This study was approved by the institutional review board (IRB No. 0406113). SRS had to be completed at least 1 week following resection. Patients were aged $>18$ years and had a Karnofsky performance status of 60 or greater. All patients were treated with CyberKnife ${ }^{\circledR}$ robotic radiosurgery system (Accuray, Sunnyvale, Calif., USA). RPA and the GPA prognostic indices were determined as previously published $[16,17,20]$, and included in a multivariate Cox regression analysis to model predictors of outcome. Table 1 shows criteria for GPA and RPA classifications.

\section{Radiosurgery Planning and Delivery}

Each patient was comfortably positioned on the CT simulation table and a custom thermoplast mask was fabricated. A thin-slice high-resolution CT with intravenous contrast was then obtained while the patient was immobilized. The acquired images were then transferred to the treatment planning workstation and fused with pretreatment thin-slice $(1.2 \mathrm{~mm})$ contrast-enhanced spoiled gradient recalled acquisition in steady state sequence MRI utilizing commercially available fusion software. The target volume and any surrounding critical structures were manually delineated by a team including a radiation oncologist, a medical physicist, and a neurosurgeon. The planning target volume was the resec- 
Table 1. Criteria for RPA and GPA

\begin{tabular}{|c|c|}
\hline RPA & GPA \\
\hline $\begin{array}{l}\text { Class I: age }<65 \text { years, KPS } \geq 70 \text {, controlled primary tumor, } \\
\text { no extracranial metastases }\end{array}$ & $\begin{array}{l}\text { Score } 0 \text { : age }>60 \text { years, KPS }<70 \text {, number of CNS metastases }>3 \text {, } \\
\text { extracranial metastases present }\end{array}$ \\
\hline Class II: all patients not in class I or III & Score 0.5 : age $50-59$ years, KPS $70-80$, number of CNS metastases $2-3$ \\
\hline Class III: KPS $<70$ & $\begin{array}{l}\text { Score } 1 \text { : age }<50 \text { years, KPS } 90-100, \text { number of CNS metastases } 1 \text {, } \\
\text { no extracranial metastases }\end{array}$ \\
\hline
\end{tabular}

KPS = Karnofsky performance status. Total GPA scores for each patient are determined by a sum of scores of the 4 variables (age, KPS, CNS metastases and extracranial metastases).

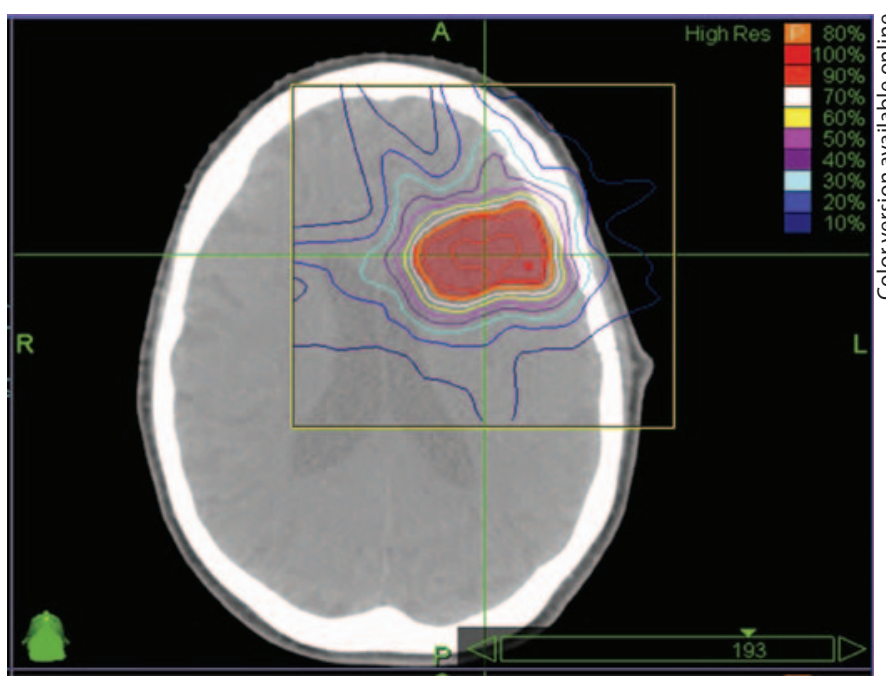

Fig. 2. Illustrative case of SRS treatment planning. This patient underwent surgical resection for left frontal brain metastasis from metastatic melanoma. Isodose lines are shown demonstrating the dose prescribed to the tumor bed (orange) and the rapid falloff of dose to the surrounding area (blue). Colors refer to the online version only.

tion cavity with a 1-mm margin. Dose volume histograms were calculated for the target volume and nearby critical structures and were utilized to select the optimal treatment plan. All patients were treated using the CyberKnife (Accuray) radiosurgery system. The median prescription dose to individual brain metastases was 18 Gy (12-27 Gy) in 1-3 fractions delivered to the $80 \%$ isodose line, where treatment sessions are offered every other day for patients undergoing fractionated regimens. Some patients had concurrent SRS to multiple lesions $(n=11)$. A representative case of treatment planning is shown in figure 2 .

\section{Statistical Analysis}

Primary end points were local control (LC), distant intracranial control rate (IC), overall survival (OS) and any observed toxicities. LC, IC, and OS rates were calculated using the Kaplan-
Meier method. Follow-up neurologic examination and MRI (or CT scanning if ineligible for MRI) were performed at 2 months after SRS, every 2-3 months for the first year, and at 3- to 6-monthly intervals thereafter. Imaging was performed to assess changes in the resection cavity, to identify the development of any new tumors, and to evaluate the risk of reactive swelling surrounding the treatment area. Local progression was defined as an increase or new development of at least $2 \mathrm{~mm}$ in the contrast-enhancing dimensions in any single plane of the resection cavity. Distant intracranial progression was defined by presence new brain metastases or leptomeningeal enhancement outside the radiosurgical treatment volume. Time of local and distant tumor recurrence was calculated from the date of radiosurgery to the first MRI that showed local or regional tumor recurrence. Prognostic factors including age, gender, number of brain metastases, tumor volume, RPA class, GPA score, new conformality index [21], primary tumor histology, extracerebral metastases, extent of surgical resection, control of primary tumor site, presence of metastases other than the resection cavity, prescription dose, maximum dose, and number of treatment sessions were assessed using multivariate analysis with Cox proportional hazards model for significant factors. All statistical analyses were performed using SPSS software version 18.0 (IBM Corp., Somers, N.Y., USA).

\section{Results}

\section{Patient and Treatment Characteristics}

Between April 2005 and July 2010, a total of 144 consecutive patients were treated with adjuvant SRS following surgical resection at a single institution. Forty-one patients were excluded because they had previous WBRT or received WBRT after surgical resection but prior to SRS. An additional 25 patients were excluded as they had subtotal resection of brain metastases. One patient was excluded for having SRS to the surgical cavity beyond 3 months after surgery. The remaining 77 patients (42 females, 35 males) with a median age of 63 years (39-88 years) and 89 metastases met the inclusion criteria for this 
Table 2. Patient and treatment characteristics

\begin{tabular}{|c|c|}
\hline Characteristic & $\mathrm{n}$ \\
\hline \multicolumn{2}{|l|}{ Sex } \\
\hline Male & $35(45)$ \\
\hline Female & $42(55)$ \\
\hline Median age, years & $63[39-83]$ \\
\hline KPS (median) & $80[60-100]$ \\
\hline \multicolumn{2}{|l|}{ Graded prognostic assessment score } \\
\hline $0-1$ & $9(11.7)$ \\
\hline $1.5-2.5$ & $53(68.8)$ \\
\hline $3-4$ & $15(19.5)$ \\
\hline \multicolumn{2}{|l|}{ Recursive partitioning analysis class } \\
\hline 1 & $17(22.1)$ \\
\hline 2 & $44(57.1)$ \\
\hline 3 & $16(20.8)$ \\
\hline \multicolumn{2}{|l|}{ Primary disease } \\
\hline NSCLC & $33(42.9)$ \\
\hline Breast & $11(14.3)$ \\
\hline Melanoma & $9(11.7)$ \\
\hline Renal cell & $7(9.1)$ \\
\hline Colorectal & $4(5.2)$ \\
\hline Other & $13(16.8)$ \\
\hline \multicolumn{2}{|l|}{ Number of metastases } \\
\hline 1 & $66(85.7)$ \\
\hline 2 & $10(13)$ \\
\hline 3 & $1(1.3)$ \\
\hline \multicolumn{2}{|l|}{ Systemic disease control } \\
\hline Active & $40(52)$ \\
\hline Controlled & $27(35)$ \\
\hline Remission & $10(13)$ \\
\hline Target volume (median), $\mathrm{cm}^{3}$ & $7.6[1.1-59]$ \\
\hline Prescription dose (median), Gy & $18[12-27]$ \\
\hline Maximum dose (median), Gy & $22.5[15-33.8]$ \\
\hline Overall biologically effective dose (median), $\mathrm{Gy}_{10}$ & $50.4[19.2-81.6]$ \\
\hline Conformality index (median) & $1.21[1.0-2.05]$ \\
\hline \multicolumn{2}{|l|}{ Number of targets } \\
\hline 1 treatment session & $64(71.9)$ \\
\hline 2 treatment sessions & $14(15.7)$ \\
\hline 3 treatment sessions & $11(12.4)$ \\
\hline Interval from surgery to SRS (median), weeks & $4.9[1.1-11.5]$ \\
\hline
\end{tabular}

Unless otherwise indicated, data presented as $\mathrm{n}(\%)$. Square brackets contain ranges.

study. Prior to SRS, the primary disease was active, in remission, and controlled in 52, 13, and $35 \%$ of patients, respectively. The median prescription dose was $18 \mathrm{~Gy}$ (12-27 Gy) delivered to the $80 \%$ isodose line, with a median target volume of $7.6 \mathrm{~cm}^{3}$ (range, $1.1-59 \mathrm{~cm}^{3}$ ) at a median 4.9 weeks (range, 1.1-11.5 weeks) from surgery. The biologically effective dose (assuming a $\alpha / \beta$ ratio of 10 for acute/tumor effects), $\mathrm{BED}_{10}$, was calculated for each tumor bed according to the formula $\mathrm{BED}_{10}(\mathrm{~Gy})=$ total dose

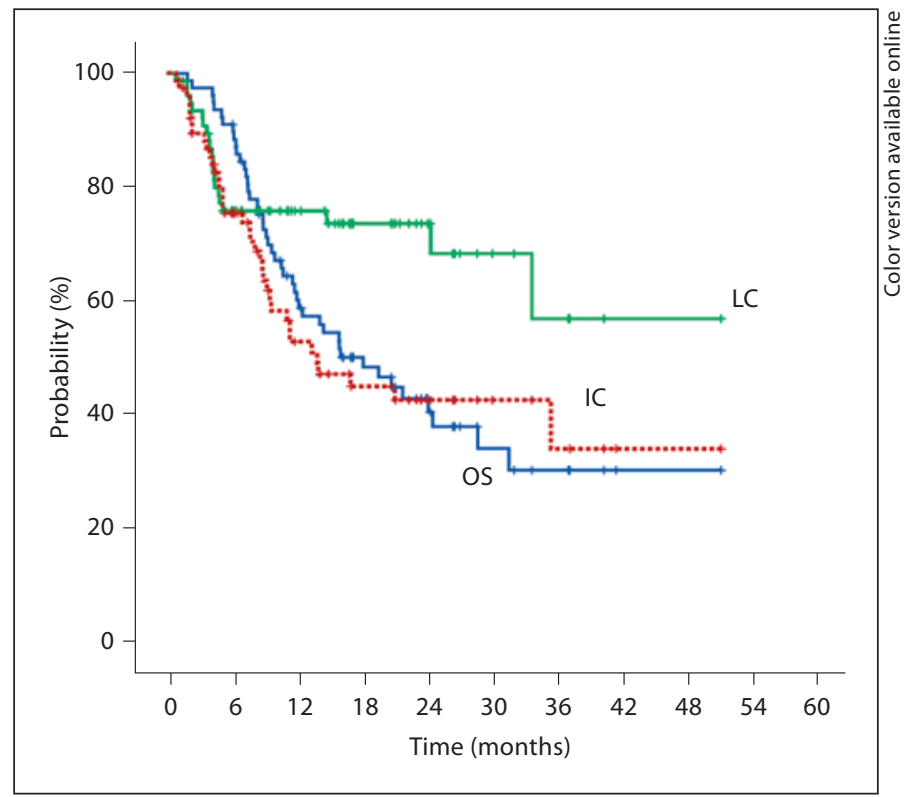

Fig. 3. Kaplan-Meier curves of LC, IC, and OS for the entire cohort.

$\times[1+($ dose per fraction $) / 10]$. The median overall $\mathrm{BED}_{10}$ was 50.4 Gy (19.2-81.6 Gy). Patient and treatment characteristics are summarized in table 2 .

\section{Clinical Outcomes}

Using MRI evaluations, 20 patients (26\%) progressed locally with a median time to progression of 4.4 months (range, 0.8-33.8 months). The overall 6-month, 1-year, and 2-year LC rates were 76.1, 76.1, and 74.3\%, respectively (fig. 3). Thirty-six patients (46.7\%) developed new brain metastases at a median of 7 months (range, $0.8-35.6$ months). The overall 6-month, 1-year, and 2-year IC rates were $75.2,54$, and $43.6 \%$, respectively (fig. 3 ).

With a median follow-up of 13.8 months, the median OS was 14.5 months (1.9-51.4 months) after SRS. The median OS for RPA classes $1(n=17), 2(n=44)$, and $3(n=$ 16) were not reached, 21.9 , and 6.2 months, respectively (fig. 4). The median OS for GPA scores [0-1] $(\mathrm{n}=9)$, [1.52.5] $(\mathrm{n}=53)$, and [3-4] $(\mathrm{n}=15)$ were 6.2 months, 18.2 months and not reached, respectively (fig. 4). The 6-month, 1-year, and 2-year OS rates were 91, 62.5, and $43.6 \%$, respectively (fig. 3).

On multivariate analysis, only target volume significantly affected local control $(\mathrm{p}=0.01)$. No factors were significantly associated with distant intracranial tumor recurrence. Factors that significantly influenced overall 


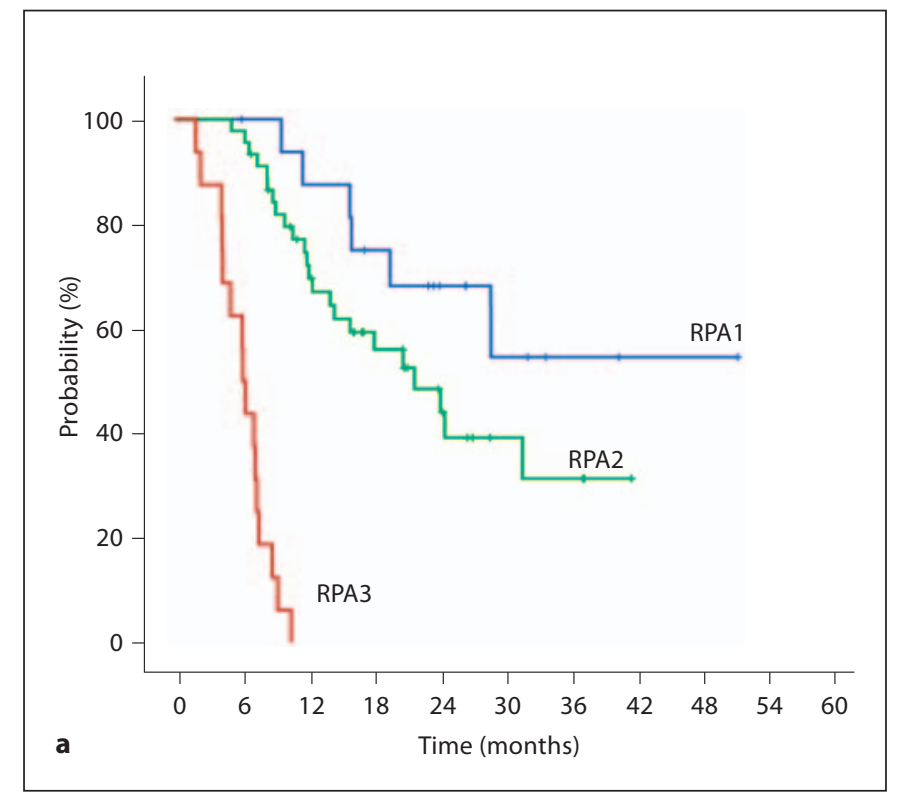

Fig. 4. Kaplan-Meier curves for OS by RPA class (a) and GPA (b).

survival on multivariate analysis were age $(\mathrm{p}=0.001)$, GPA score $(\mathrm{p}=0.01)$, and RPA class $(\mathrm{p}=0.02)$.

Toxicity was limited and included 2 patients who experienced radiation necrosis. One patient was initially treated with 21 Gy in 1 fraction to a target volume of 3.7 $\mathrm{cm}^{3}$ and she required surgical resection 10 months after SRS. The second patient was treated with $25 \mathrm{~Gy}$ in 3 fractions to a target volume of $33 \mathrm{~cm}^{3}$, and he died of lung cancer shortly thereafter. Forty-four patients (57.1\%) had died at last follow-up. Of 34 patients with a known cause of death, $19(55.9 \%)$ died of neurologic cause at a median 11.7 months (6.4-31.7 months).

\section{Salvage Therapy}

Overall, 20 patients (26\%) required WBRT for local and intracranial disease progression at a median 8.8 months (2.2-17.3 months) after SRS. Of 20 patients with local tumor recurrence, $16(80 \%)$ were treated with SRS $(\mathrm{n}=6)$, repeated resection plus SRS to cavity $(\mathrm{n}=1)$, resection $(\mathrm{n}=2)$, repeated resection plus WBRT $(\mathrm{n}=1)$, WBRT and repeated resection $(\mathrm{n}=1)$, and WBRT only $(\mathrm{n}=5)$.

Among those with distant intracranial tumor recurrence $(\mathrm{n}=36), 12$ patients had SRS, 3 patients had repeat resection plus WBRT, and 10 patients had WBRT including a patient who developed leptomeningeal carcinomatosis shortly after development of new brain lesions. The

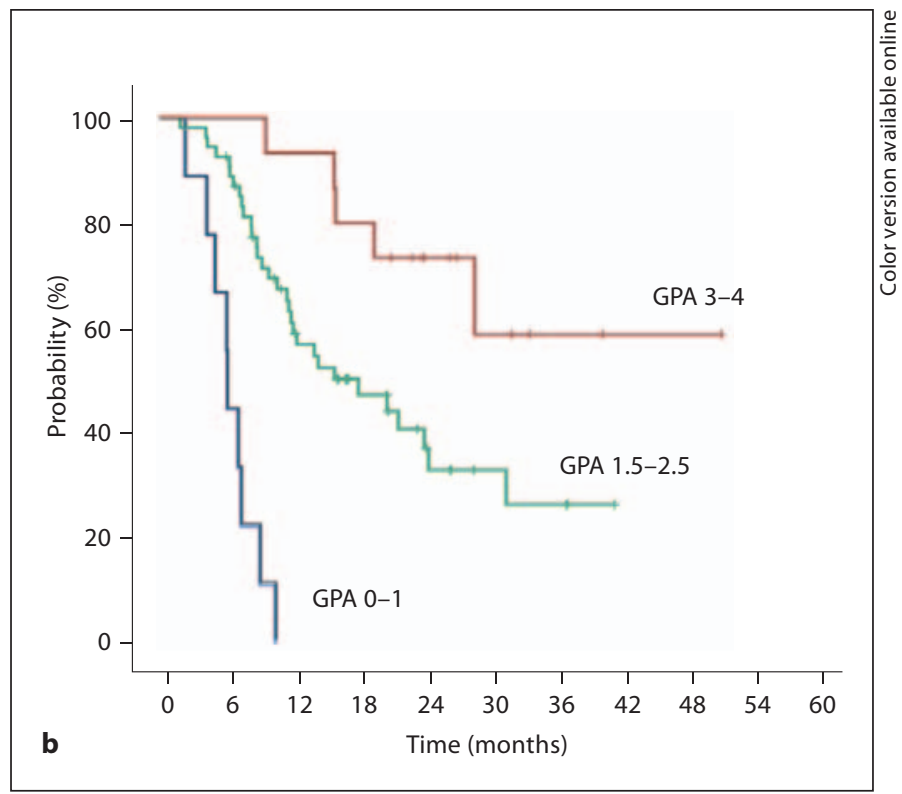

remaining 11 patients had significant co-morbidities that precluded initiation of salvage radiotherapy at the time of last follow-up.

\section{Discussion}

Brain metastases are a common complication of systemic cancer and occur in up to $40 \%$ of patients [22]. Historically, the development of brain metastases has been associated with a poor prognosis, with patient survival times being on the order of less than 3 months on glucocorticoid therapy alone [23]. WBRT became a widely accepted treatment modality after reported improvement in OS [24]. Patchell et al. [25] and Vecht et al. [26] reported that a more aggressive approach using surgical resection followed by WBRT improved resulted in improved survival compared to WBRT alone. However, some authors suggest that in patients with limited disease, WBRT should be delayed to decrease the risk of long-term decline in neurocognition and the impact that this can have on the quality of life of patients [5]. Moreover, Chang et al. [27] recently showed in a prospective randomized trial that the use of upfront WBRT in addition to SRS is associated with significant decline in learning and memory function, and suggested using SRS alone in patients with RPA class I-II as initial therapy to 
maintain adequate quality of life. Therefore, SRS has more recently emerged as an effective alternative treatment option in patients with limited brain metastases and continues to be studied as an adjuvant therapy to resection and as an alternative to WBRT after resection. In this study, we present outcomes of this approach, where patients with 1-3 brain metastases were treated with adjuvant SRS after resection and received WBRT only as salvage therapy. To our knowledge, the current series represents the largest series evaluating this treatment option using CyberKnife SRS.

Currently, there are no randomized trials comparing surgery plus WBRT to surgery plus SRS; however, many retrospective studies have suggested that both combined treatment approaches can attain equivalent disease control [6-10]. In our series, local control was achieved in $74 \%$ of patients with actuarial 1-year and 2 -year LC rates of 76.1 and $74.3 \%$, respectively, with a median follow-up of 13.1 months. These results are in keeping with the previously reported data (table 2). However, our crude LC rate of $74 \%$ is lower than another 2 series that used $\mathrm{Cy}$ berKnife (table 2). Soltys et al. [10] reported $86 \%$ overall LC in 72 patients; however, they had a short median follow-up of only 8.1 months that could have resulted in an overestimation of their local control rate. In addition, they also reported that a $2-\mathrm{mm}$ margin in a subset of their patients resulted in improved local control compared to those with narrower margins, and obtained a $70 \%$ LC rate in those treated without a margin. Jagannathan et al. [2] also used a 2- to 3-mm margin and reported a $94 \%$ overall LC in 47 patients with a median follow-up of only 10 months. In our study, we used a 1-mm margin around the surgical cavity in all patients. There are other published data that may argue against the direct correlation of larger margins with local control. Kresl et al. [28] used a 2- to 3-mm margin but observed a 30\% local failure rate, albeit at a median dose of 16 Gy which may be somewhat lower than most previous studies. In another recent study by Kelly et al. [29], they did not add margins to the resection cavity and reported an $89 \%$ LC at a median follow-up of 12.7 months in 17 patients only. Lower dose in some of our patients may also have contributed to lower LC rate. Seventeen percent of the lesions in our study received a dose lower than the median prescription dose of $18 \mathrm{~Gy}$, including 3 lesions that had $12 \mathrm{~Gy}$. While this dose seems low compared with the median dose of previously published studies (table 2), dose guidelines to the resection cavity are still under investigation and low dose is often used in this setting where the target is microscopic disease. Our $26 \%$ local recurrence rate can be also compared to the $46 \%$ recurrence rate of patients in Patchell's trial that did not have postoperative adjuvant radiotherapy [13], underlining the need for some form of adjuvant radiation. Our local recurrence rates were similar to other postoperative SRS trials with longer median follow-up, including 27\% in Mathieu et al. [8] and 24\% in Iwai et al. [6]. It is important to note that the length of median follow-up is critically important when determining the local recurrence rate.

Our results showed a median overall survival of 14.5 months, which is similar to previously published series (table 2). When patients were stratified by RPA classes and GPA scores, both prognostic indices were highly predictive of OS. The majority of deaths were from neurologic disease mainly due to the development of new metastases consistent with failure of IC control. Overall, $47.4 \%$ of patients developed new metastases during follow-up, and these comprised the majority of those requiring salvage WBRT. Twenty-seven percent of our patients required salvage WBRT for either intracranial recurrence or local tumor recurrence at a median 8.8 months following SRS. These results compare favorably to $47 \%$ reported by Do et al. [30], and $40 \%$ reported by Limbrick et al. [7], and are similar to $30 \%$ shown by Karlovits et al. [31]. Soltys et al. [10] and Mathieu et al. [8] both had lower salvage WBRT rates of 19 and 16\%, respectively; however, at shorter respective median intervals of 6.1 and 4 months. The recent EORTC 22952-26001 phase III trial randomized patients to WBRT or observation after surgery or radiosurgery for 1-3 brain metastases [32]. The study showed that adjuvant WBRT reduces both intracranial recurrence and neurologic deaths, but does not improve the duration of functional independence and OS. Even though this situation is not analogous to our study design, these results further support holding WBRT in stable patients with limited disease until required as salvage therapy.

Given the low rate of treatment-related toxicities seen with SRS compared to WBRT, the prospect for SRS in the postoperative setting is compelling considering the possibility of further optimizing local control through careful radiosurgical planning with inclusion of wider margins where appropriate, and taking into account other factors that may affect local control including size of surgical cavity as noted in this study.

Delaying the contouring of the postoperative cavity until 2-3 weeks following resection allows more refined distinction of postsurgical changes from residual disease and allows for more accurate tumor contouring. In addition, increased latency between surgery and SRS can be 
Table 3. Review of studies reporting results of adjuvant SRS for resected brain metastases

\begin{tabular}{|c|c|c|c|c|c|c|c|c|c|}
\hline & $\mathrm{n}$ & SRS technique & $\begin{array}{l}\text { Follow-up (me- } \\
\text { dian), months }\end{array}$ & $\begin{array}{l}\text { Solitary } \\
\text { lesions, \% }\end{array}$ & $\begin{array}{l}\text { Dose } \\
\text { Gy }\end{array}$ & $\begin{array}{l}\text { Gross-total } \\
\text { resection, } \%\end{array}$ & $\begin{array}{l}\text { Local } \\
\text { control, \% }\end{array}$ & $\begin{array}{l}\text { Median OS } \\
\text { months }\end{array}$ & $\begin{array}{l}\text { Salvage } \\
\text { WBRT, \% }\end{array}$ \\
\hline Kresl et al. [28] & 61 & Gamma Knife & 18.3 & 100 & 16 (median) & 52 & 70 & 14.9 & 23 \\
\hline Soltys et al. [10] & 72 & CyberKnife & 8.1 & 65 & 18.6 (median) & 85 & 86 & 15.1 & 19 \\
\hline Mathieu et al. [8] & 40 & Gamma Knife & 13 & 67.5 & 16 (median) & 80 & 73 & 13 & 16 \\
\hline Iwai et al. [6] & 21 & Gamma Knife & 21.6 (mean) & 76 & 17 (mean) & 100 & 76 & 20 & 9.5 \\
\hline Do et al. [30] & 30 & linac & NA & 43.3 & 16 (median) & 62.2 & 88 & 12 & 47 \\
\hline Jagannathan et al. [2] & $47^{\mathrm{a}}$ & Gamma Knife & 10 & NA & 19 (mean) & 100 & 94 & $10^{\mathrm{b}}$ & 21 \\
\hline Karlovits et al. [31] & 52 & linac & 13 & 65.4 & 15 (median) & 92.3 & 93 & 15 & 30 \\
\hline Limbrick et al. [7] & 15 & Gamma Knife & 20 & 73.3 & 20 (median) & 72.2 & 73.3 & 20 & 40 \\
\hline Hwang et al. [37] & 25 & Gamma Knife & NA & NA & 15-20 (range) & 95 & 84 & 15 & NA \\
\hline Jensen et al. [38] & 106 & Gamma Knife & NA & 57.5 & 17 (median) & 96.4 & 80 & 10.9 & 36.8 \\
\hline Kalani et al. [39] & 68 & Gamma Knife & NA & 100 & 15 (median) & 100 & 79 & 13.2 & NA \\
\hline Kelly et al. [29] & $17^{\mathrm{c}}$ & CyberKnife & 12.7 & 71 & 18 (median) & 94.4 & 89 & 15 & 41 \\
\hline Present study & 77 & CyberKnife & 13.8 & 85.7 & 18 (median) & 100 & 74 & 14.5 & 27.2 \\
\hline
\end{tabular}

a Three patients received adjuvant WBRT prior to SRS. ${ }^{b}$ Reported as median duration until death. ${ }^{c}$ One patient had previous WBRT.

associated with greater shrinkage of the resection cavity allowing smaller SRS targets. However, significant delay of SRS may affect the outcome of treatment as the resection cavity may show tumor regrowth and it remains unknown whether using the larger immediate postoperative volume compared to delayed contouring results in better tumor control.

Local treatment options investigated as adjuvant therapy of resected brain metastases also include low-dose rate brachytherapy. Results of brachytherapy for postoperative treatment of single brain metastases using the GliaSite Radiation Therapy System in lieu of WBRT were reported by Rogers et al. [33]. They achieved an overall LC of $83 \%$ following a median 60 Gy delivered to $1-\mathrm{cm}$ margin around the surgical cavity. However, they also noted a $14.5 \%$ incidence of radiation-induced necrosis. In our series, most patients tolerated the treatment without toxicity and we observed only 2 cases of radiation necrosis. Some of our physicians opted to fractionate the prescription dose for larger surgical cavities, which may have further minimized dose to normal tissues and potentially contributed to low rates of complications.

At our institution, we have established a long history of SRS for brain metastases using the Gamma Knife [3436], including experience with radiosurgery to the resection cavity [7]. Others have similarly demonstrated the efficacy of Gamma Knife radiosurgery in the adjuvant setting [37-39]. Accuracy of treatment delivery using the Gamma Knife and CyberKnife has been reported to be similar for intracranial lesions with both systems [4042]. Our data in the current series extends the literature showing similar clinical outcomes among the multiple trials for various SRS platforms (table 3).

In summary, adjuvant frameless linac-based CyberKnife radiosurgery to the tumor cavity of resected brain metastases is well tolerated, achieves local control in the majority of patients and is associated with a low incidence of toxicity. In patients with oligo-metastatic disease, postoperative SRS to the resection cavity with close radiological follow-up and repeated SRS to new lesions provide satisfactory local control rates and allows for the elimination or postponement of WBRT in the majority of patients. A phase III randomized clinical trial should be conducted to validate the benefit of SRS after resection in comparison to resection plus WBRT, with neurocognitive and quality of life included in primary endpoints. RPA class and GPA are highly predictive of outcome and should be utilized to stratify patients in future studies.

\section{Acknowledgement}

J.-C.M.R. was supported by the American Society for Radiation Oncology (ASTRO 2010 Medical Student Fellowship Award).

\section{Disclosure Statement}

The authors state that they have no conflicts of interest. 


\section{References}

1 Brem S, Panattil JG: An era of rapid advancement: diagnosis and treatment of metastatic brain cancer. Neurosurgery 2005;57:S5-S9.

$\checkmark 2$ Jagannathan J, Yen CP, Ray DK, Schlesinger D, Oskouian RJ, Pouratian N, Shaffrey ME, Larner J, Sheehan JP: Gamma Knife radiosurgery to the surgical cavity following resection of brain metastases. J Neurosurg 2009;111:431-438.

$\checkmark 3$ Bradley KA, Mehta MP: Management of brain metastases. Semin Oncol 2004;31:693701.

-4 Sun A, Bae K, Gore EM, Movsas B, Wong SJ, Meyers CA, Bonner JA, Schild SE, Gaspar LE, Bogart JA, Werner-Wasik M, Choy $\mathrm{H}$ : Phase III trial of prophylactic cranial irradiation compared with observation in patients with locally advanced non-small-cell lung cancer: neurocognitive and quality-oflife analysis. J Clin Oncol 2011;29:279-286.

5 Marko NF, Weil RJ: Radiotherapy: neurocognitive considerations in the treatment of brain metastases. Nat Rev Clin Oncol 2010; 7:185-186.

6 Iwai Y, Yamanaka K, Yasui T: Boost radiosurgery for treatment of brain metastases after surgical resections. Surg Neurol 2008;69: 181-186.

$\checkmark 7$ Limbrick DD Jr, Lusis EA, Chicoine MR, Rich KM, Dacey RG, Dowling JL, Grubb RL, Filiput EA, Drzymala RE, Mansur DB, Simpson JR: Combined surgical resection and stereotactic radiosurgery for treatment of cerebral metastases. Surg Neurol 2009;71:280288

$\checkmark 8$ Mathieu D, Kondziolka D, Flickinger JC, Fortin D, Kenny B, Michaud K, Mongia S, Niranjan A, Lunsford LD: Tumor bed radiosurgery after resection of cerebral metastases. Neurosurgery 2008;62:817-823.

D9 Quigley MR, Fuhrer R, Karlovits S, Karlovits B, Johnson M: Single session stereotactic radiosurgery boost to the post-operative site in lieu of whole brain radiation in metastatic brain disease. J Neurooncol 2008;87:327332.

>10 Soltys SG, Adler JR, Lipani JD, Jackson PS, Choi CY, Puataweepong P, White S, Gibbs IC, Chang SD: Stereotactic radiosurgery of the postoperative resection cavity for brain metastases. Int J Radiat Oncol Biol Phys 2008;70:187-193.

$>11$ Rwigema JC, Heron DE, Ferris RL, Gibson M, Quinn A, Yang Y, Ozhasoglu C, Burton $S$ : Fractionated stereotactic radiation body therapy in previously-irradiated recurrent head and neck carcinoma: updated report of the University of Pittsburgh Experience. Am J Clin Oncol 2010;33:286-293.

$\checkmark 12$ Rwigema JC, Parikh SD, Heron DE, Howell M, Zeh H, Moser AJ, Bahary N, Quinn A, Burton SA: Stereotactic body radiotherapy in the treatment of advanced adenocarcinoma of the pancreas. Am J Clin Oncol 2011;34: 63-69.
13 Patchell RA, Tibbs PA, Regine WF, Dempsey RJ, Mohiuddin M, Kryscio RJ, Markesbery WR, Foon KA, Young B: Postoperative radiotherapy in the treatment of single metastases to the brain: a randomized trial. JAMA 1998;280:1485-1489.

14 Chow E, Davis L, Holden L, Tsao M, Danjoux C: Prospective assessment of patient-rated symptoms following whole brain radiotherapy for brain metastases. J Pain Symptom Manage 2005;30:18-23.

15 Ueki K, Matsutani M, Nakamura O, Tanaka Y: Comparison of whole brain radiation therapy and locally limited radiation therapy in the treatment of solitary brain metastases from non-small cell lung cancer. Neurol Med Chir (Tokyo) 1996;36:364-369.

16 Gaspar L, Scott C, Murray K, Curran W: Validation of the RTOG recursive partitioning analysis (RPA) classification for brain metastases. Int J Radiat Oncol Biol Phys 2000; 47:1001-1006.

17 Gaspar L, Scott C, Rotman M, Asbell S, Phillips T, Wasserman T, McKenna WG, Byhard R: Recursive partitioning analysis (RPA) of prognostic factors in three Radiation Therapy Oncology Group (RTOG) brain metastases trials. Int J Radiat Oncol Biol Phys 1997; 37:745-751.

18 Weltman E, Salvajoli JV, Brandt RA, de Morais Hanriot R, Prisco FE, Cruz JC, de Oliveira Borges SR, Wajsbrot DB: Radiosurgery for brain metastases: a score index for predicting prognosis. Int J Radiat Oncol Biol Phys 2000; 46:1155-1161.

19 Lorenzoni J, Devriendt D, Massager N, David P, Ruíz S, Vanderlinden B, Van Houtte P Brotchi J, Levivier M: Radiosurgery for treatment of brain metastases: estimation of patient eligibility using three stratification systems. Int J Radiat Oncol Biol Phys 2004;60: 218-224.

20 Sperduto PW, Berkey B, Gaspar LE, Mehta $\mathrm{M}$, Curran W: A new prognostic index and comparison to three other indices for patients with brain metastases: an analysis of 1,960 patients in the RTOG database. Int J Radiat Oncol Biol Phys 2008;70:510-514.

21 Nakamura JL, Verhey LJ, Smith V, Petti PL, Lamborn KR, Larson DA, Wara WM, McDermott MW, Sneed PK: Dose conformity of gamma knife radiosurgery and risk factors for complications. Int J Radiat Oncol Biol Phys 2001;51:1313-1319.

22 Johnson JD, Young B: Demographics of brain metastasis. Neurosurg Clin N Am 1996;7:337-344.

23 Weissman DE: Glucocorticoid treatment for brain metastases and epidural spinal cord compression: a review. J Clin Oncol 1988;6: 543-551.
24 Borgelt B, Gelber R, Kramer S, Brady LW, Chang $\mathrm{CH}$, Davis LW, Perez CA, Hendrickson FR: The palliation of brain metastases: final results of the first two studies by the $\mathrm{Ra}$ diation Oncology Group. Int J Radiat Oncol Biol Phys 1980;6:1-9.

25 Patchell RA, Tibbs PA, Walsh JW, Dempsey RJ, Maruyama Y, Kryscio RJ, Markesbery WR, Macdonald JS, Young B: A randomized trial of surgery in the treatment of single metastases to the brain. N Engl J Med 1990;322: 494-500.

26 Vecht CJ, Haaxma-Reiche H, Noordijk EM, Padberg GW, Voormolen JH, Hoekstra FH, Tans JT, Lambooij N, Metsaars JA, Wattendorff AR: Treatment of single brain metastasis: radiotherapy alone or combined with neurosurgery? Ann Neurol 1993;33:583590.

27 Chang EL, Wefel JS, Hess KR, Allen PK, Lang FF, Kornguth DG, Arbuckle RB, Swint JM, Shiu AS, Maor MH, Meyers CA: Neurocognition in patients with brain metastases treated with radiosurgery or radiosurgery plus whole-brain irradiation: a randomised controlled trial. Lancet Oncol 2009; 10:10371044.

28 Kresl J, Pueschel J, Porter R, Yan E, McDermott M, Sneed P: Surgical resection and postoperative radiosurgery for single brain metastases (abstracts). Neurooncology 2003; $5: 338$.

29 Kelly PJ, Lin YB, Yu AY, Alexander BM, Hacker F, Marcus KJ, Weiss SE: Stereotactic irradiation of the postoperative resection cavity for brain metastasis: a frameless linear accelerator-based case series and review of the technique. Int J Radiat Oncol Biol Phys 2010, E-pub ahead of print.

30 Do L, Pezner R, Radany E, Liu A, Staud C, Badie B: Resection followed by stereotactic radiosurgery to resection cavity for intracranial metastases. Int J Radiat Oncol Biol Phys 2009;73:486-491.

-31 Karlovits BJ, Quigley MR, Karlovits SM, Miller L, Johnson M, Gayou O, Fuhrer R: Stereotactic radiosurgery boost to the resection bed for oligometastatic brain disease: challenging the tradition of adjuvant wholebrain radiotherapy. Neurosurg Focus 2009; 27:E7.

32 Kocher M, Soffietti R, Abacioglu U, Villà S, Fauchon F, Baumert BG, Fariselli L, TzukShina T, Kortmann RD, Carrie C, Hassel MB, Kouri M, Valeinis E, van den Berge D, Collette S, Collette L, Mueller RP: Adjuvant whole-brain radiotherapy versus observation after radiosurgery or surgical resection of one to three cerebral metastases: results of the EORTC 22952-26001 study. J Clin Oncol 2011;29:134-141. 
-33 Rogers LR, Rock JP, Sills AK, Vogelbaum MA, Suh JH, Ellis TL, Stieber VW, Asher AL, Fraser RW, Billingsley JS, Lewis P, Schellingerhout D, Shaw EG: Results of a phase II trial of the GliaSite radiation therapy system for the treatment of newly diagnosed, resected single brain metastases. J Neurosurg 2006;105:375-384

>34 Kondziolka D, Kano H, Harrison GL, Yang HC, Liew DN, Niranjan A, Brufsky AM, Flickinger JC, Lunsford LD: Stereotactic radiosurgery as primary and salvage treatment for brain metastases from breast cancer. J Neurosurg 2011;114:792-800.

>35 Liew DN, Kano H, Kondziolka D, Mathieu D, Niranjan A, Flickinger JC, Kirkwood JM, Tarhini A, Moschos S, Lunsford LD: Outcome predictors of Gamma Knife surgery for melanoma brain metastases. J Neurosurg 2011;114:769-779.
36 Niranjan A, Kano H, Khan A, Kim IY, Kondziolka D, Flickinger JC, Lunsford LD: Radiosurgery for brain metastases from unknown primary cancers. Int J Radiat Oncol Biol Phys 2010;77:1457-1462.

37 Hwang SW, Abozed MM, Hale A, Eisenberg RL, Dvorak T, Yao K, Pfannl R, Mignano J, Zhu JJ, Price LL, Strauss GM, Wu JK: Adjuvant Gamma Knife radiosurgery following surgical resection of brain metastases: a 9-year retrospective cohort study. J Neurooncol 2010;98:77-82.

38 Jensen CA, Chan MD, McCoy TP, Bourland JD, Deguzman AF, Ellis TL, Ekstrand KE, McMullen KP, Munley MT, Shaw EG, Urbanic JJ, Tatter SB: Cavity-directed radiosurgery as adjuvant therapy after resection of a brain metastasis. J Neurosurg 2010, E-pub ahead of print.
39 Kalani MY, Filippidis AS, Kalani MA, Sanai N, Brachman D, McBride HL, Shetter AG, Smith KA: Gamma Knife surgery combined with resection for treatment of a single brain metastasis: preliminary results. J Neurosurg 2010;113:90-96.

40 Chang SD, Gibbs IC, Heilbrun MP: An analysis of the accuracy of the CyberKnife ${ }^{\circledR}$ : a robotic frameless stereotactic radiosurgical system. Neurosurgery 2003;52:140-147.

41 Maciunas RJ, Cobb C, Zaccharias E, Moore A, Mandava VR: An independent application accuracy evaluation of stereotactic frame systems. Stereotact Funct Neurosurg. 1992;58:103-107.

42 Rohlfing T, Maurer CR Jr, Dean D, Maciunas RJ: Effect of changing patient position from supine to prone on the accuracy of a BrownRoberts-Wells stereotactic head frame system. Neurosurg 2003;52:610-618. 